\title{
Synthesis, Characterization and Biological Activate 5-(Hydroxymethyl) Pyrrolidin-2-One at Room Temperature
}

\section{Veerappan Jeyachandran $1^{*}$}

${ }^{1}$ Department of Chemistry, Bharath Institute of Higher Education and Research, Selaiyur, Chennai, Tamil Nadu, India

*Corresponding author e-mail: jeyorg@gmail.com

\section{Article Info}

Volume 8, Issue 1

Page Number: 10-15

Publication Issue :

January-February-2021

\section{ABSTRACT}

A new class of chiral pyrrolidinone was synthesized from (5S)-5[(trityloxy)methyl] pyrrolidin-2-one (6) (Schemes 1 and 2). The synthetic design followed led to the insertion of various substituents at 1 and 5 of the pyrrolidinone moiety. Some of them possess two or three stereo centers, here configuration was retained under the mild condition. The new compounds also carry an imidazole moiety, which, along with the 2-pyrrolidinone template, may prove pivotal to several biological processes.

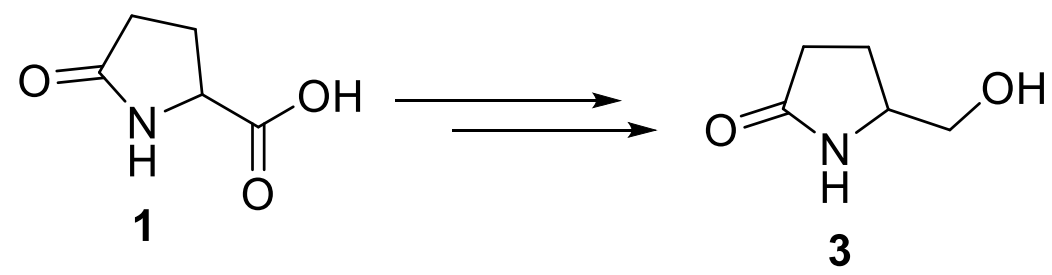

The chiral pyrrolidinone $(\mathrm{R})$ ring is incorporatedin various compounds with biological and pharmaceutical activities [1]. some of them are well known medicines, e.g., doxapram for patients with respiratory failure,piracetam for patients with Alzheimer's seizures, and senile dementia, concussion and other neurological problems [2,3]. The properties and applications of pyroglutamic acid as a versatile building block in asymmetric synthesis has extensively been reviewed in the literature[4,5]. Some of them exhibited anti-inflammatory and antihypertensive activity [6,7]

Keywords: Pyroglutamic Acid, Anti-Inflammatory, Doxapram And Alzheimer's Seizures

Copyright: (C) the author(s), publisher and licensee Technoscience Academy. This is an open-access article distributed under the terms of the Creative Commons Attribution Non-Commercial License, which permits unrestricted noncommercial use, distribution, and reproduction in any medium, provided the original work is properly cited 


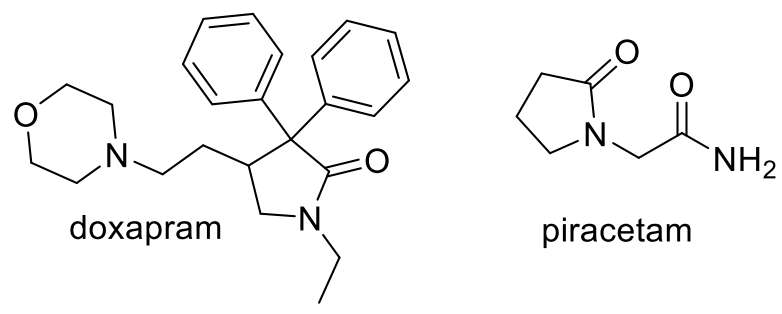

In recent years, we have designed and synthesized 2-pyrrolidinones, starting from the naturally derived 2oxotetrahydropyrrol-5S-carboxylic acid, which is considered as a unique chiral synthon [8].

\section{Experimental}

\section{GENERAL}

The melting pointswere measured in open capillary tubes and are uncorrected. The ${ }^{1} \mathrm{H}$ and ${ }^{13} \mathrm{C}$ NMR spectra were recorded on a Bruker (Avance) $300 \mathrm{MHz}$ NMR instrument using TMS as internal standard and DMSO as solvent. Standard Bruker software was used throughout. Chemical shifts are given in parts per million ( $\square$-scale) and the coupling constants are given in Hertz [9]. Elemental analyses were performed on a Perkin Elmer 2400 Series II Elemental CHNS analyzer. Silica gel-G plates (Merck) were used for tlc analysis with a mixture of petroleum ether $\left(60-80^{\circ} \mathrm{C}\right)$ and ethyl acetate as eluent. All the chemicals were purchased from Aldrich and used without any further purification.

\section{Synthesis of ethyl-5-oxopyrrolidine (2)}

In the present work, the reaction of pyroglutamic acid $1(1 \mathrm{mmol})$ in $\mathrm{EtOH}$ was added drop wise $\mathrm{SOCl}_{2}(1.2$ $\mathrm{mmol}$ ). The resulting solution was stirred for overnight, the reaction was monitored by TLC, after completion of the reaction neutralized with saturated $\mathrm{NaHCO}_{3}$ and extracted with $\mathrm{CHCl}_{3}$. The combined organics were dried $\left(\mathrm{Na}_{2} \mathrm{SO}_{4}\right)$ and the solvent was removed under reduced pressure to give a green oil which was purified by reduced pressure distillation to afford ethyl-5- oxopyrrolidine2 (82\%) as a white solid by known literature method [10].

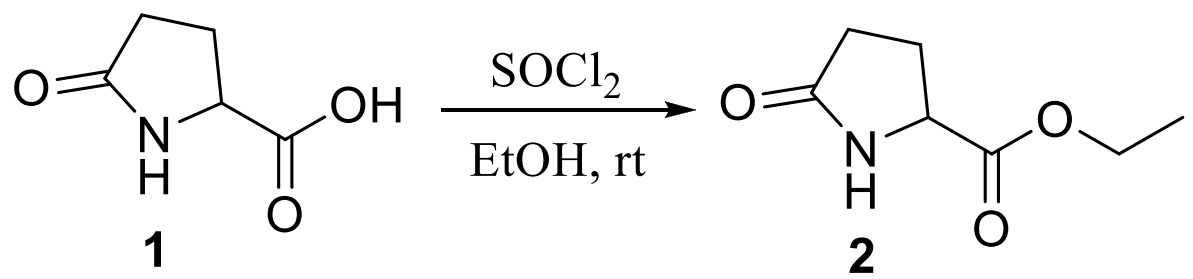

Scheme 1. Synthesis of ethyl-5-oxopyrrolidine 2

Isolated as green oil; Yield 82\%; ${ }^{1} \mathrm{H}$ NMR (300 MHz, $\left.\mathrm{CDCl}_{3}\right) \delta_{\mathrm{H}} 1.31$ (t, 3H, J =7.0), 2.27-2.15 (m, 1H), 2.52-2.32 $(\mathrm{m}, 3 \mathrm{H}), 4.24$ (q, 2H, J= 7.0), 4.29-4.17 (m, 1H) and 7.23 (br s, $1 \mathrm{H}, \mathrm{NH})$. 


\section{Synthesis of ethyl-5-oxopyrrolidine (3)}

Sodium borohydride $(1 \mathrm{mmol})$ was added portion wise, over $15 \mathrm{~min}$, to a solution of ethyl-2-pyrrolidinone- 5carboxylate $2(1 \mathrm{mmol})$ in ethanol. The reaction mixture was allowed to stir at room temperature for additional 2-4 h. After completion of the reaction $\mathrm{HCl}(12 \mathrm{M})$ was added to the reaction mixture and the resulting mixture was filtered. The filtrate was concentrated in vacuum to give crude ethyl-5-oxopyrrolidine 3 , which was used for the next step [10].<smiles>CCCCCOC(=O)C1CCC(=O)N1</smiles>

Scheme 2. Synthesis of ethyl-5-oxopyrrolidine 3

Isolated as colourless oil; Yield 80\%; ${ }^{1} \mathrm{H}$ NMR $\left(300 \mathrm{MHz}, \mathrm{CDCl}_{3}\right) \delta_{\text {н }} 1.75-1.83(\mathrm{~m}, 1 \mathrm{H}), 2.10-2.21$ (m, $\left.1 \mathrm{H}\right), 2.31-$ 2.44 (m, 2H), 3.45 (dd, J=11.0, 6.8, 1H), 3.73 (dd, J=11.0, 3.1, 1H), 3.80 (m, 1H), 4.56 (br s, 1H), 7.60 (br s, 1H).

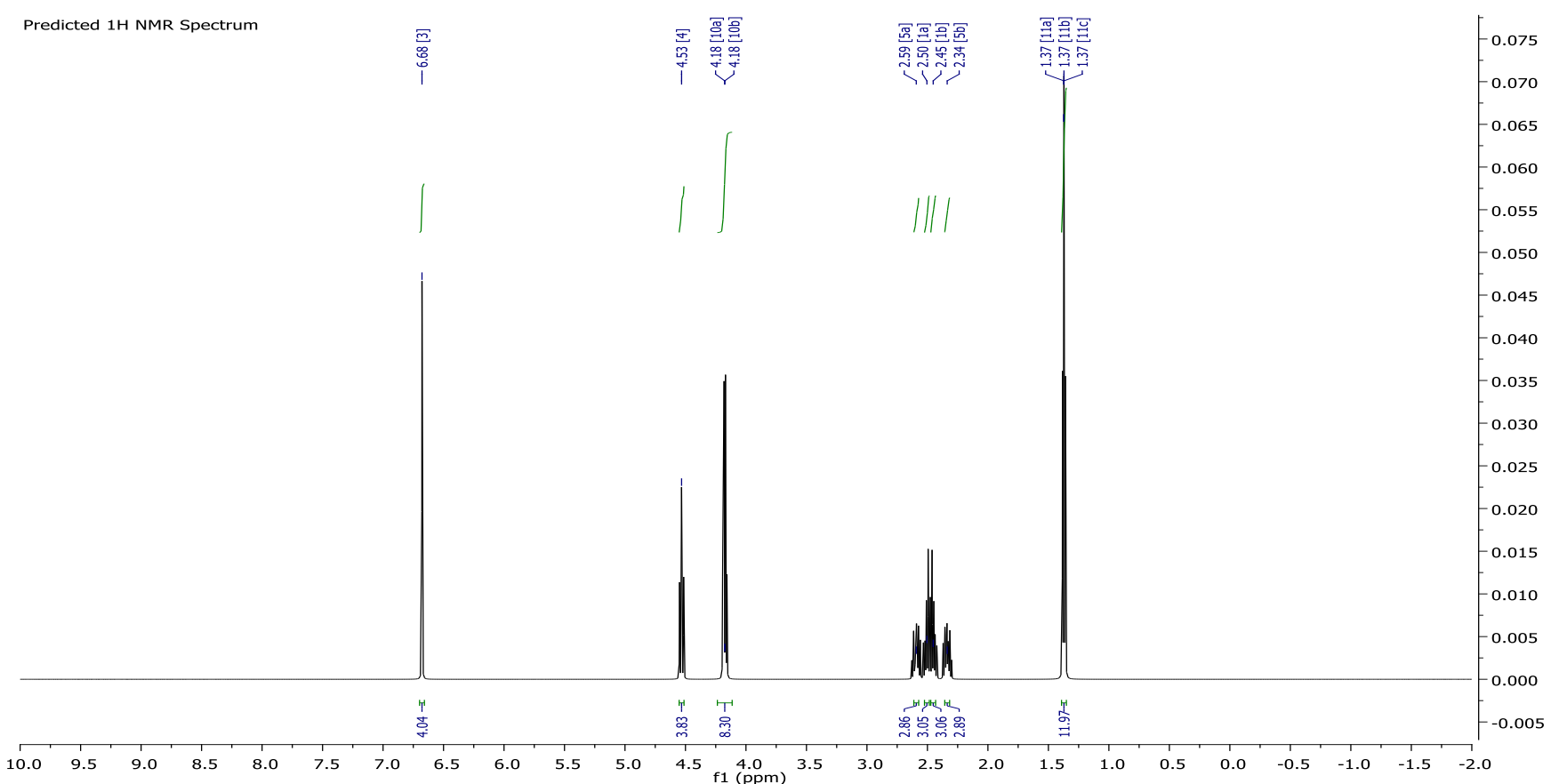

Figure 1. ${ }^{1} \mathrm{H}$ NMR spectrum of 2 


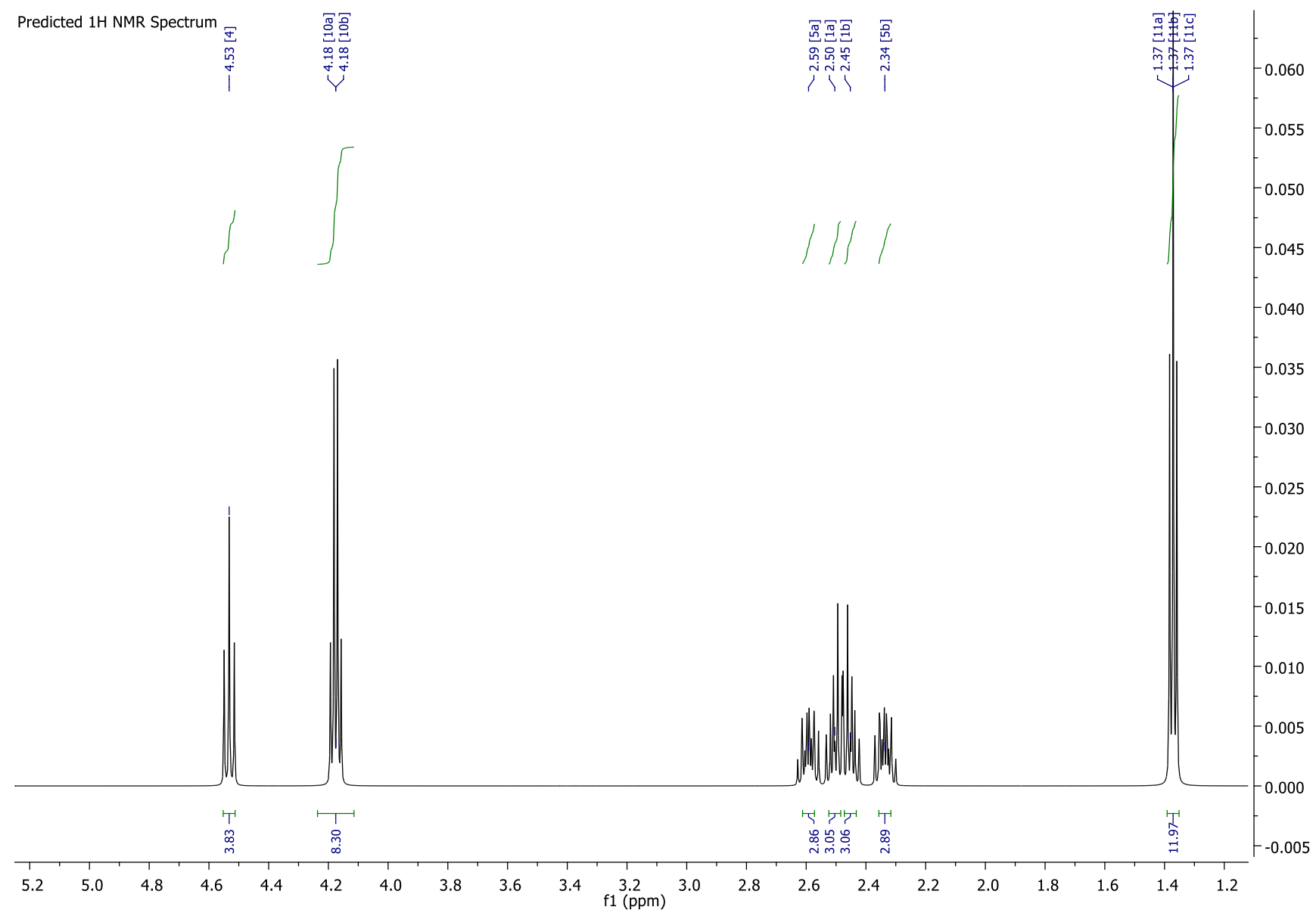

Figure 3. ${ }^{1} \mathrm{H}$ NMR (expanded) spectrum

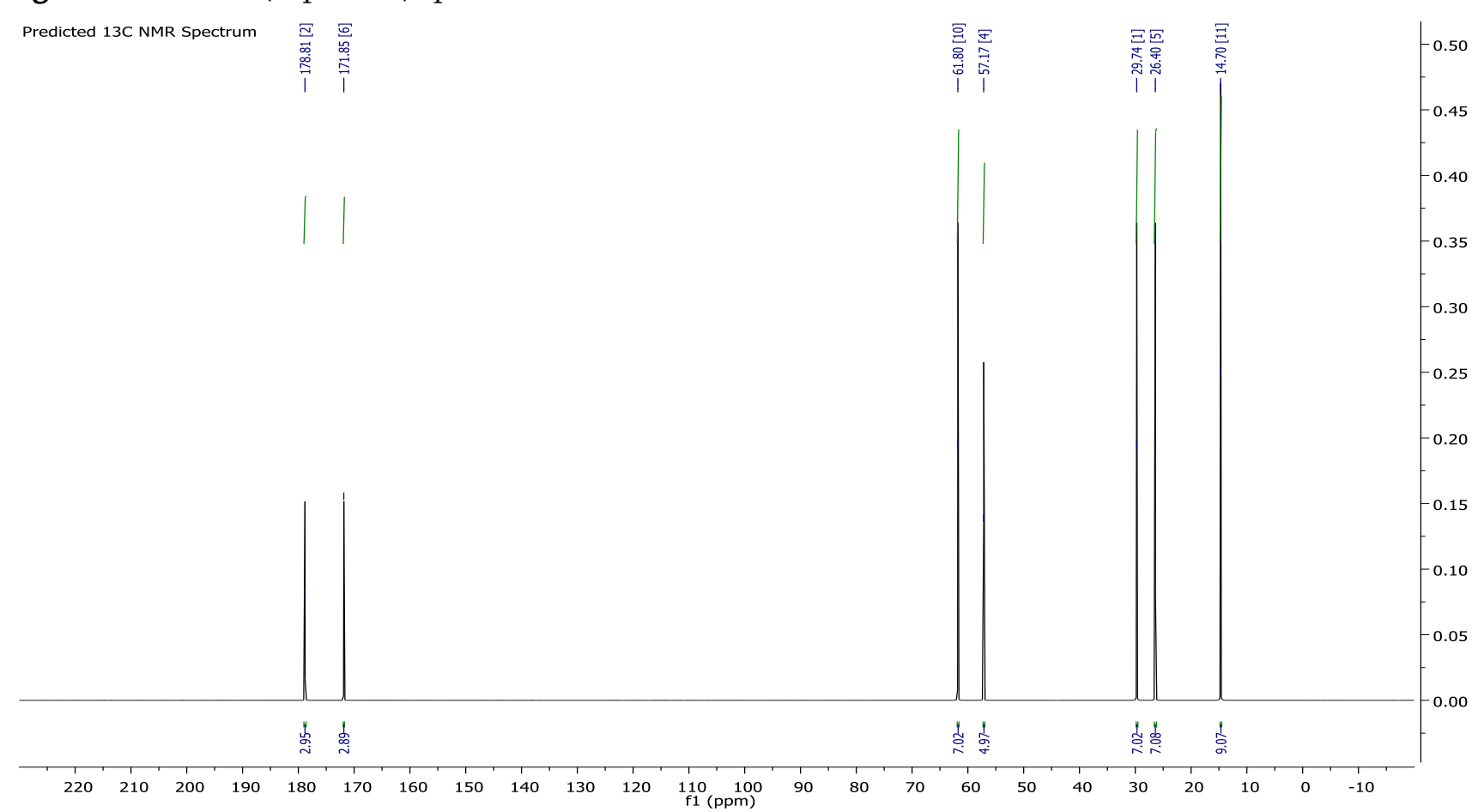

Figure $4 .{ }^{13} \mathrm{C}$ NMR spectrum of 2 
Veerappan Jeyachandran Int J Sci Res Sci \& Technol. January-February-2021; 8 (1) : 10-15

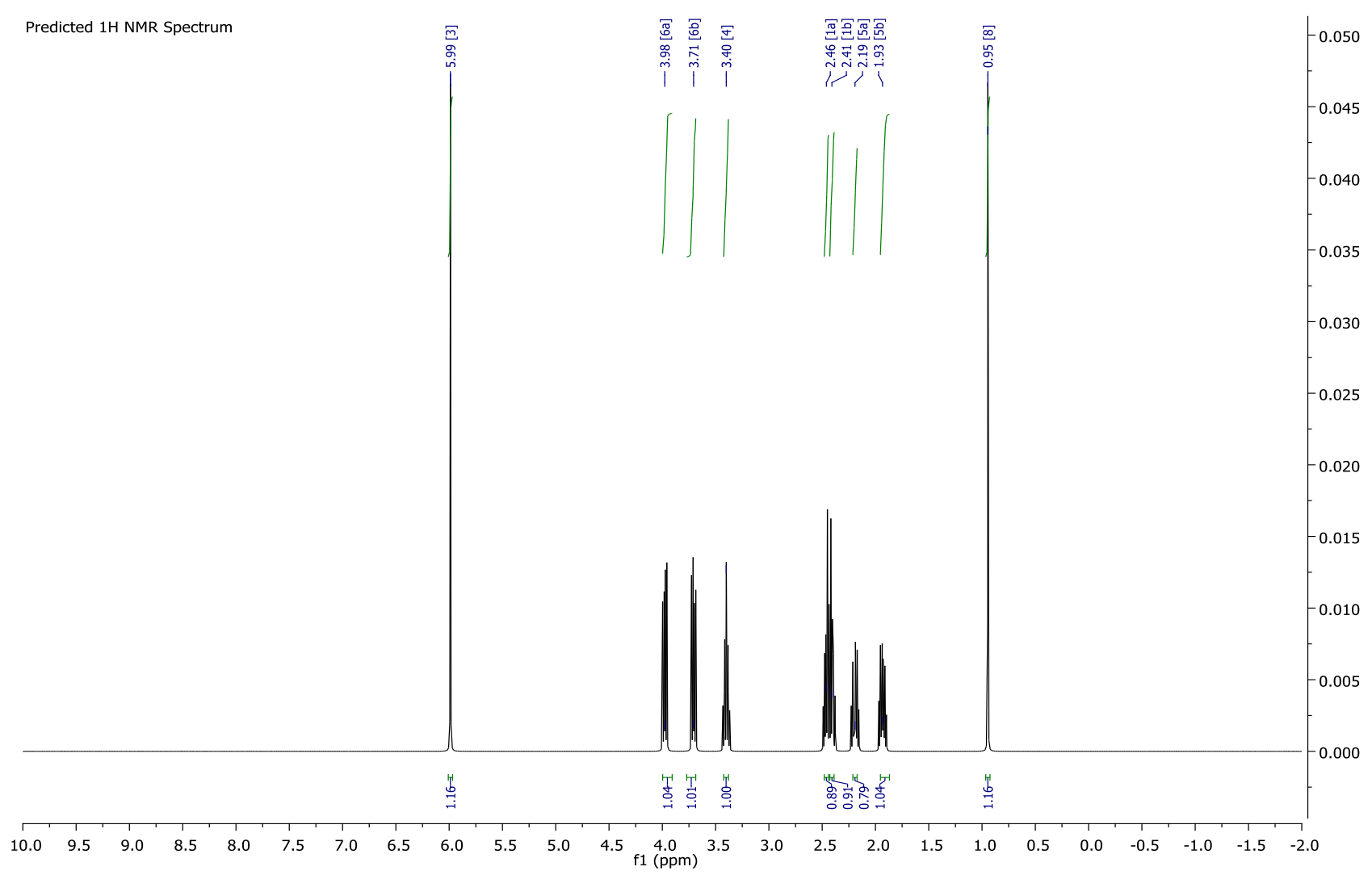

Figure 5. ${ }^{1} \mathrm{H}$ NMR spectrum of 3

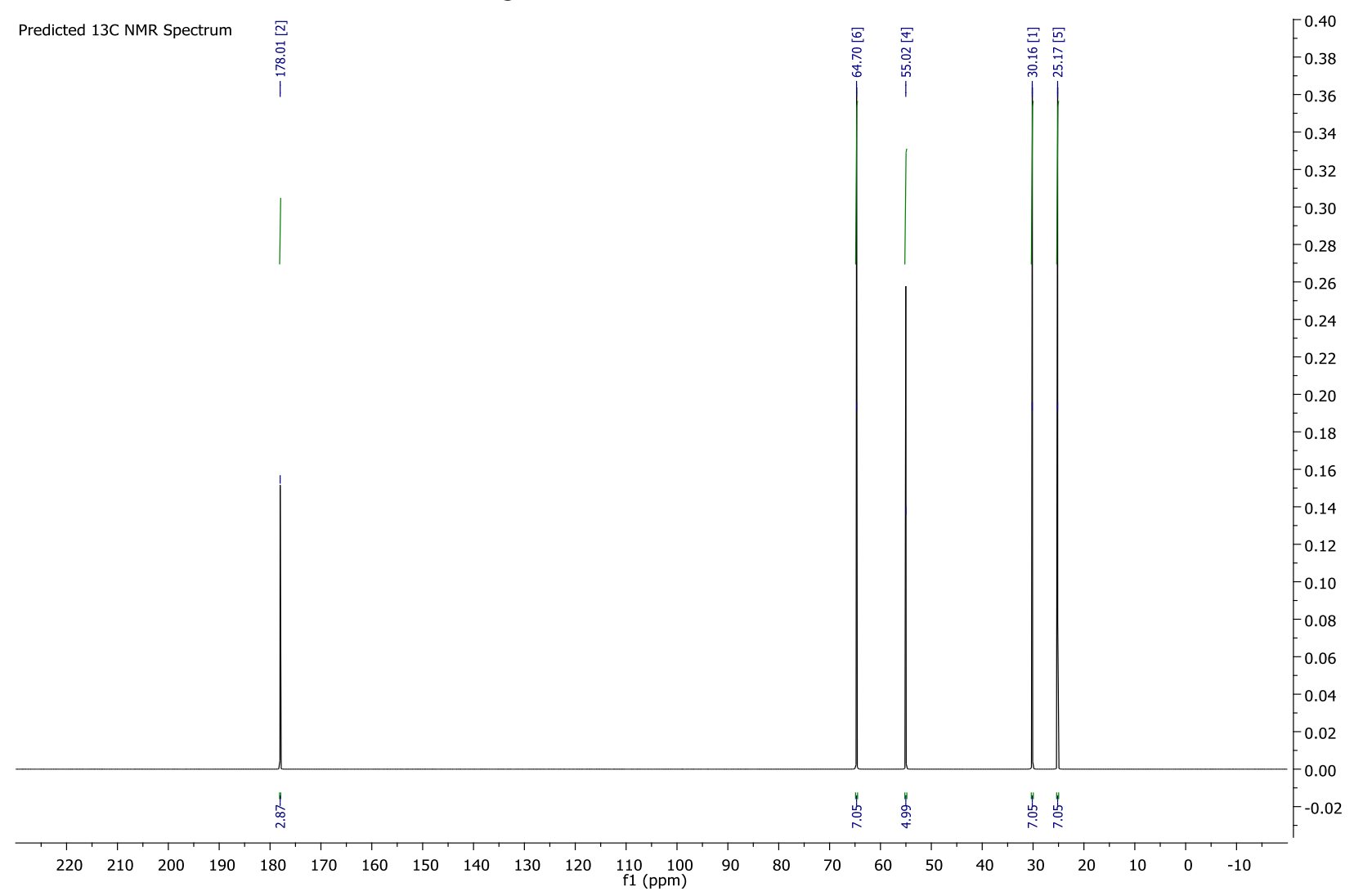

Figure 6. ${ }^{13} \mathrm{C}$ NMR spectrum of $\mathbf{3}$ 


\section{CONFLICT OF INTEREST}

The authors declare no conflict of interest.

\section{ACKNOWLEDGMENTS}

The encouragement and support from Bharath University, Chennai is gratefully acknowledged. For provided the laboratory facilities to carry out the research work.

\section{REFERENCES}

[1]. F. Felluga, V. Gombac, G. Pitacco, E. Valentin, E. Zangrando, S. Morganti, E. Rizzato, D. Spinelli, G. Petrillo, Tetrahedron 2006, 62, 8787 - 8791.

[2]. Singh, P.; Dimitriou, V.; Malajan, R.P.; Crossley, A.W. Double-blind comparison between doxapram and pethidine in the treatment of postanaesthetic shivering. Br. J. Anaesth. 1993, 71, 685-688.

[3]. Winbal, B. Piracetam: A review of pharmacological properties and clinical uses. CNS Drug Rev. 2005, 11, 169-182

[4]. Panday, S.K.; Prasad, J.; Dikshit, K.D. Pyroglutamic acid: A unique chiral synthon. Tetrahedron: Asymmetry 2009, 20, 1581-1632.

[5]. Coppola, G.M.; Schuster, H.F. Asymmetric Synthesis. Construction of Chiral Molecules Using Amino Acids; John Wiley: New York, NY, USA, 1987

[6]. Moutevelis-Minakakis, P.; Papavassilopoulou, E.; Michas, G.; Georgikopoulou, K.; Ragoussi, M.E.; Neophytou, N.; Zoumpoulakis, P.; Mavromoustakos, T.; Hadjipavlou-Litina, D. Bioorg. Med. Chem. 2011, 19, 2888-2902.

[7]. Mavromoustakos, T.; Moutevelis-Minakakis, P.; Kokotos, C.G.; Kontogianni, P.; Politi, A.; Zoumpoulakis, P.; Findlay, A.; Cox, A.; Balmforth, A.; Zoga, A.Bioorg. Med. Chem. 2006, 14, 4353-4360.

[8]. Mavromoustakos, T.; Fotakis, C.; Siapi, E.; Potamitis, C.; Viras, K.; Moutevelis-Minakakis, P.; Kokotos, G.; Durgasi, S.; Grdadolnik, S.; Sartori, B BBA-Biomembranes, 2010, 1798, 422-432.

[9]. Panday, S.K.; Prasad, J.; Dikshit, K.D. Pyroglutamic acid: A unique chiral synthon. Tetrahedron: Asymmetry 2009,20, 1581-1632

[10]. Moutevelis-Minakakis, P.; Gianni, M.; Stougiannou, H.; Zoumpoulakis, P.; Zoga, A.; Vlahakos, E.; Iliodromitis, E.; Mavromoustakos, Bioorg. Med. Chem. Lett. 2003, 13, 1737-1740.

\section{Cite this article as :}

Veerappan Jeyachandran, "Synthesis, Characterization and Biological Activate 5-(Hydroxymethyl) Pyrrolidin2-One at Room Temperature", International Journal of Scientific Research in Science and Technology (IJSRST), Online ISSN : 2395-602X, Print ISSN : 2395-6011, Volume 8 Issue 1, pp. 10-15, January-February 2021. Available at doi : https://doi.org/10.32628/IJSRST207668

Journal URL : http://ijsrst.com/IJSRST207668 